\title{
Design of Permanent Magnet Synchronous Motor Control System for Electric Vehicle Air Conditioning Compressor Based on Vector Control
}

\author{
Kuan Shi, Yongjun Chen*, Zhou He, Jie Wang, Yinsheng Li \\ College of Electronics and Information, Yangtze University, Jingzhou, China \\ Email: ${ }^{\star} 1136575583 @ q q . c o m$
}

How to cite this paper: Shi, K., Chen, Y.J., He, Z., Wang, J. and Li, Y.S. (2019) Design of Permanent Magnet Synchronous Motor Control System for Electric Vehicle Air Conditioning Compressor Based on Vector Control. Open Access Library Journal, 6: e5157.

https://doi.org/10.4236/oalib.1105157

Received: December 29, 2018

Accepted: January 13, 2019

Published: January 16, 2019

Copyright $\odot 2019$ by author(s) and Open Access Library Inc.

This work is licensed under the Creative

Commons Attribution International

License (CC BY 4.0).

http://creativecommons.org/licenses/by/4.0/

\begin{abstract}
Permanent magnet synchronous motor (PMSM) has the advantages of small size, light weight, simple structure, reliable operation, high power factor, easy heat dissipation and easy maintenance. It has become the best choice for electric vehicle air conditioner compressors, but in actual working conditions, the air conditioner compressor has the problem of excessive noise and serious system turbulence, which makes the air conditioner compressor unable to work normally, which has serious consequences. The method of using the field oriented control can overcome the problems existing under actual working conditions, so it proposed the design of permanent magnet synchronous motor control system for electric vehicle air conditioner compressor.
\end{abstract}

\section{Subject Areas}

Electric Engineering

\section{Keywords}

Air Conditioning Compressor, Permanent Magnet Synchronous Motor, Electric Vehicle, Vector Control

\section{Introduction}

Permanent magnet synchronous motors are increasingly being applied to machine tool servo systems, elevator drives, electric vehicle propulsion, and air conditioning compressors. Automotive air conditioning compressors are the 
core part of electric vehicle air conditioners, solving the problem of excessive noise and serious system oscillation [1].

Permanent magnet synchronous motor (PMSM) has the characteristics of small size, simple structure, high power factor, reliable operation, easy heat dissipation and easy maintenance. It has been widely used in machine tool servo system, elevator drive, electric vehicle propulsion, air conditioner compressor, etc. [2]. Compared with ordinary air conditioner compressors, PMSM has significant advantages in the application of electric vehicle air conditioner compressors. PMSM has the characteristics of wide speed regulation range, high control precision and small torque ripple [3]. With the development of high-speed microprocessors, advances in power electronics, and continuous improvement of control algorithms, the application of PMSM technology has become more mature and extensive. Based on the actual working conditions of electric vehicle air conditioner compressor, based on the analysis of PMSM vector control working principle, the design of permanent magnet synchronous motor control system for electric vehicle air conditioner compressor is completed. With dsPIC30F4011 as the core, electric vehicle air conditioner compressor is constructed, PMSM control system.

In the traditional automotive system, the compressor and the car-driven engine need to be used together, and the car must be started before the car air-conditioning compressor can work normally. In the electric vehicle system, the whole system is electric, and the compression system does not need to rely on the driving of the automobile wheel engine. Up to now, the air conditioning system has become an independent part, as a separate unit, with independent power supply system and vehicle main system. The signal transmission through communication enables individual control and variable frequency control functions. The efficiency ratios of the compressor's traditional mechanical mode and electric mode are shown in Table 1.

\section{The principle of PMSM Work}

\subsection{The Mathematical Model of PMSM}

To simplify the analysis, assume that the magnetic path of the PMSM is not saturated and the spatial magnetic field is sinusoidal, ignoring hysteresis and eddy current losses [4].

The direction of the PMSM rotor permanent magnet magnetic field is defined as the d-axis, and the $\mathrm{d}$-axis is orthogonal to the $\mathrm{q}$-axis. The $\mathrm{dq}$ coordinate

Table 1. Comparison of the efficiency of the traditional mechanical mode and electric mode of the compressor.

\begin{tabular}{ccccc}
\hline Model mode & $\begin{array}{c}\text { Volumetric } \\
\text { efficiency }\end{array}$ & $\begin{array}{c}\text { Transmission } \\
\text { efficiency }\end{array}$ & Others & Comprehensive \\
\hline Motor drive & 0.9 & 0.65 & 0.75 & 0.44 \\
Mechanical drive & 0.4 & 0.95 & 0.75 & 0.29 \\
\hline
\end{tabular}


system is fixed on the rotor, rotates synchronously with the rotor, and the angle between the $\mathrm{d}$-axis and the A-axis is a variable, physical model [5].

The mathematical model of the PMSM in the synchronously rotated $\mathrm{d}-\mathrm{q}$ coordinate system is established as follows.

Motor flux linkage equation:

$$
\left\{\begin{array}{l}
\psi_{d}=L_{d} i_{d}+\psi_{f} \\
\psi_{q}=L_{q} i_{q}
\end{array}\right.
$$

Torque equation:

$$
T_{e}=\frac{3}{2} P_{n}\left(\psi_{d} i_{q}-\psi_{q} i_{d}\right)
$$

Stator voltage equation:

$$
\left\{\begin{array}{l}
u_{d}=R_{s} i_{d}+\frac{\mathrm{d} \psi_{d}}{\mathrm{~d} t}-\omega_{e} \psi_{q} \\
u_{q}=R_{s} i_{q}+\frac{\mathrm{d} \psi_{q}}{\mathrm{~d} t}+\omega_{e} \psi_{d}
\end{array}\right.
$$

Equation of motion:

$$
T_{e}-T_{L}=J \frac{\mathrm{d} \omega_{m}}{\mathrm{~d} t}+B \omega_{m}
$$

$L_{d}, L_{q}-\mathrm{d}$, q-axis equivalent inductance;

$\psi_{f}$-Permanent magnet flux linkage;

$R_{s}$-Stator resistance;

$\omega_{e}, \omega_{m}$-Electrical angular velocity and mechanical angular velocity;

$T_{e}$-Electromagnetic torque;

$p_{n}$ - Magnetic pole pair;

$T_{L}$ - Load torque;

$J$-Moment of inertia;

$B$-Coefficient of friction.

According to formula (3), it can be concluded:

$$
T_{e}=\frac{3}{2} p_{n} \psi_{d} i_{q}=\frac{3}{2} p_{n}\left(L_{d} i_{d}+\psi_{f}\right) i_{q}=\frac{3}{2} p_{n} \psi_{f} i_{q}
$$

as follows:

$$
T_{e}=\frac{3}{2} p_{n} \psi_{f} i_{q}
$$

It can be known from the above equation that the electromagnetic torque of the motor is determined only by the q-axis current, which realizes the decoupling of the electromagnetic torque of the motor. Therefore, it can be seen that after the control strategy of $i_{d}=0$, the permanent magnet synchronous motor is equivalent to a single-excitation DC motor, and only the torque current $i_{q}$ can be controlled to control the electromagnetic torque, thereby realizing the speed control. The schematic diagram of PMSM vector control is shown in Figure 1. 


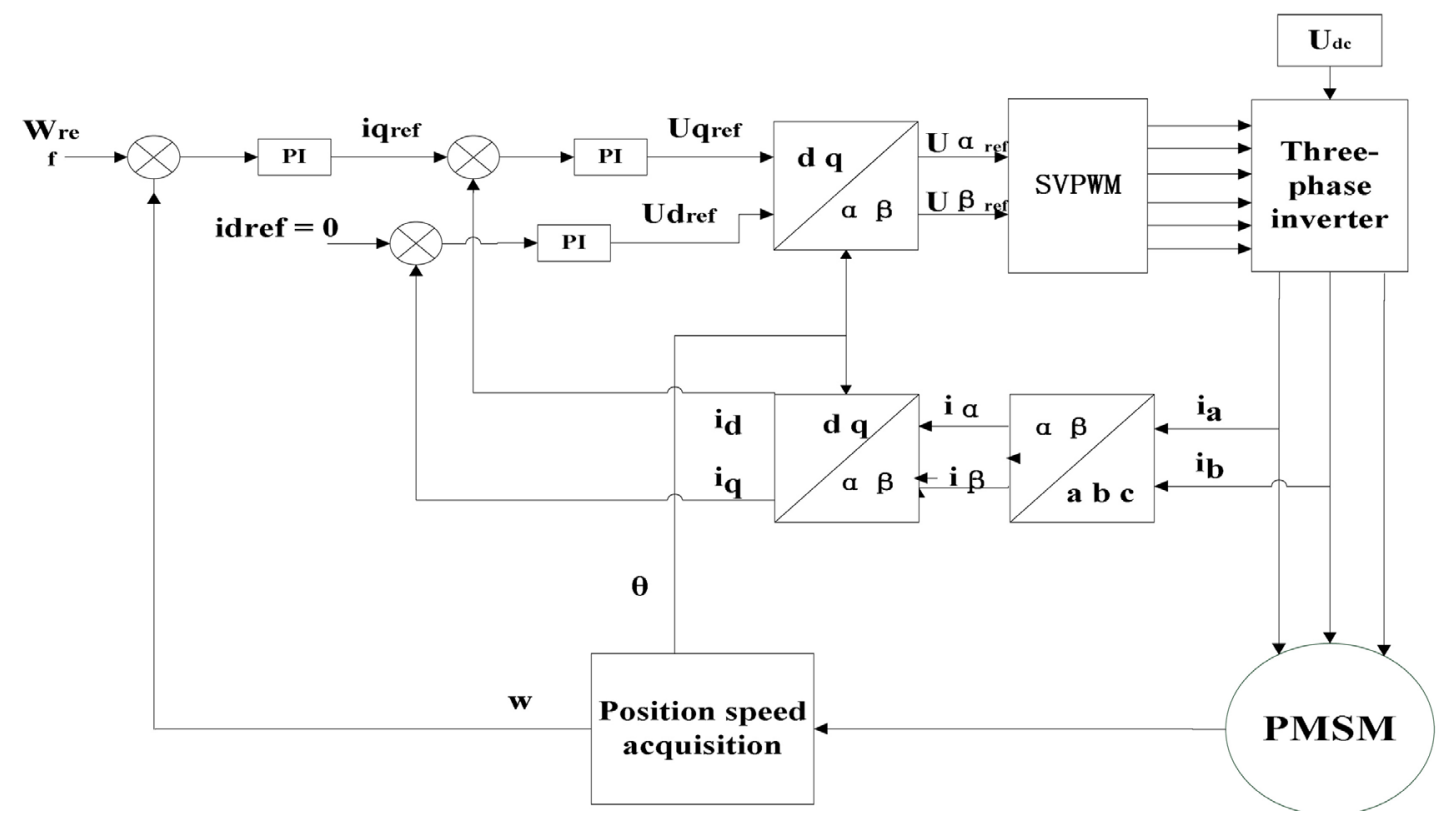

Figure 1. PMSM vector control schematic.

\subsection{Principle of PMSM Control}

SVPWM refers to outputting different pulse sequences according to different combinations of three switching tubes of the upper arm of the three-phase inverter bridge for controlling the inverter output three-phase sinusoidal voltage or three-phase sinusoidal current [6].

The six switching devices are controlled by six control signals. Each group of upper and lower bridge switching devices can only be turned on and the other is turned off. Therefore, the inverter has eight working states, corresponding to eight voltage vectors. Set the upper bridge to conduct, the lower bridge is marked as 1 , the lower bridge is turned on, and the upper bridge is closed as 0 . The formula for the phase voltage can be derived:

$$
\left[\begin{array}{l}
u_{a} \\
u_{b} \\
u_{c}
\end{array}\right]=\frac{1}{3} U_{d c}\left[\begin{array}{ccc}
2 & -1 & -1 \\
-1 & 2 & -1 \\
-1 & -1 & 2
\end{array}\right]\left[\begin{array}{l}
a \\
b \\
c
\end{array}\right]
$$

$u_{a}, u_{b}, u_{c}$-Three-phase stator phase voltage in A-B-C coordinate system.

Using the Clark transform, $u_{\alpha}, u_{\beta}$ in the $\alpha-\beta$ coordinate system can be obtained.

$$
\left[\begin{array}{l}
u_{\alpha} \\
u_{\beta}
\end{array}\right]=\sqrt{\frac{2}{3}}\left[\begin{array}{ccc}
1 & -\frac{1}{2} & -\frac{1}{2} \\
0 & \frac{\sqrt{3}}{2} & -\frac{\sqrt{3}}{2}
\end{array}\right]\left[\begin{array}{l}
u_{a} \\
u_{b} \\
u_{c}
\end{array}\right]
$$

The eight voltage vector distributions are shown in Figure 2.

From the above figure, there are 6 non-zero vector amplitudes in the 8 basic space voltage vectors, the phase difference is $60^{\circ}$, the vector space is divided into 6 sectors, and the other 2 are zero vectors. According to the parallelogram rule, 


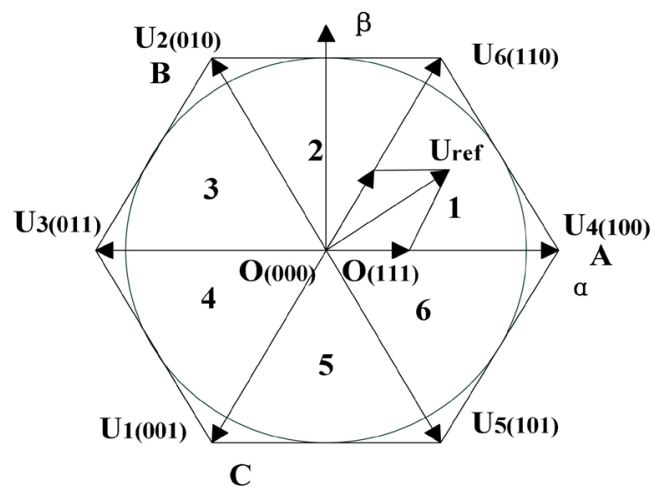

Figure 2. Basic space vector.

these 8 basic space vectors can be used to synthesize any voltage vector that does not exceed the maximum amplitude [7]. SVPWM technology uses these 8 basic space vectors to approximate a given reference voltage vector $U_{\text {ref }}$.

\section{Design of PMSM Control System}

\subsection{Hardware Design of PMSM Control System}

The hardware structure of the permanent magnet synchronous motor control system for electric vehicle air conditioner compressor is shown in Figure 3. It can be seen from Figure 3 that the hardware structure of the control system consists of three parts: control module, communication module and power module.

Among them, the control chip is dsPIC30F4011, which is a high-performance 16-bit digital signal controller with low-power high-speed flash technology, wide operating voltage range and efficient and fast working speed. It can be reprogrammed under software control, power management mode to meet system requirements.

The power module input terminal is connected to $230 \mathrm{~V}$ high-voltage DC power to supply power to the power module and the control module. The step-down is achieved by using a high frequency transformer. The DC-DC Converter UC2843 is used to control the switching of the MOS tube, and the direct current is converted into a high-frequency oscillation pulse waveform, and a low-voltage alternating current is generated by the transformer. After low-voltage AC rectification, the output voltage of the control chip is output via the three-terminal regulator LM117.

Communication circuit uses optocoupler isolation, which can be abnormal in the input signal. The protection chip is not burned out intelligent power module. Barrier protection function, when there are temperature, current, voltage and other faults, the FO pin of the module will output a fault signal to stop the motor, thereby playing a protective role.

\subsection{Software Design of PMSM Control System}

In addition to the hardware system, the control system requires software to 


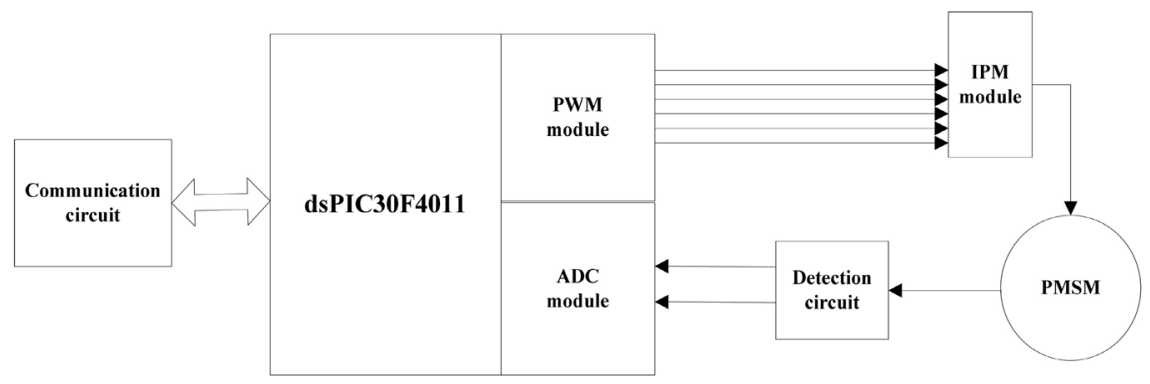

Figure 3. Control system hardware structure.
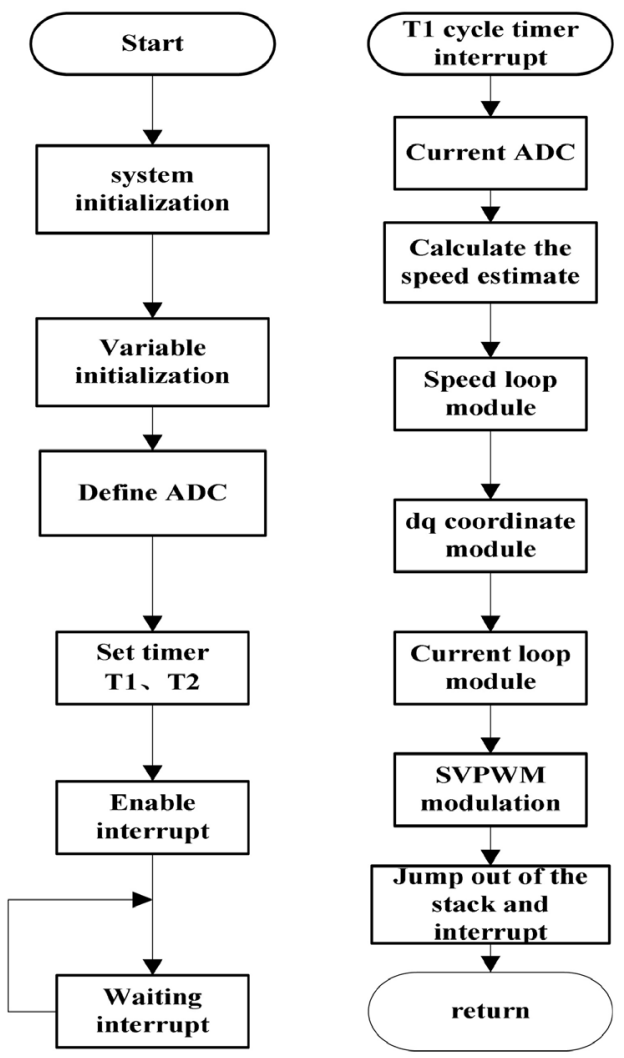

(1) Main program

(2) Interrupt return subroutine

Figure 4. Block diagram.

implement the functions of the system. The main function of this software is to realize the FOC and subroutine modules of permanent magnet synchronous motor, making full use of dsPIC30F4011 chip computing function and software filtering. The whole program is developed in the chip-specific development environment MPLAB with $C$ language. The software system has good real-time and reliability, which is convenient for modification and debugging.

The control program consists of a main program and an interrupt service subroutine. The specific process block diagram is shown in Figure 4.

\section{Experimental Results and Analysis}

The structure of the body, rotor and stator of the motor used in the drive system 
are shown in Figure 5 and Figure 6.

The technical specifications of the motor used in this control system are shown in Table 2.

Figures 7-9 are waveform diagrams of the respective phase currents measured at $n=1570 \mathrm{r} / \mathrm{min}, n=2370 \mathrm{r} / \mathrm{min}$, and $n=3350 \mathrm{r} / \mathrm{min}$.

\section{Conclusion}

The permanent magnet synchronous motor control system of electric vehicle air

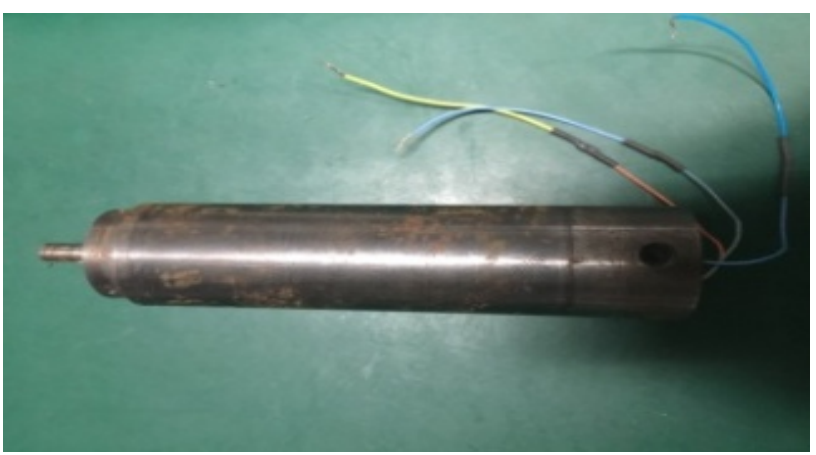

Figure 5. Structure diagram of motor body.

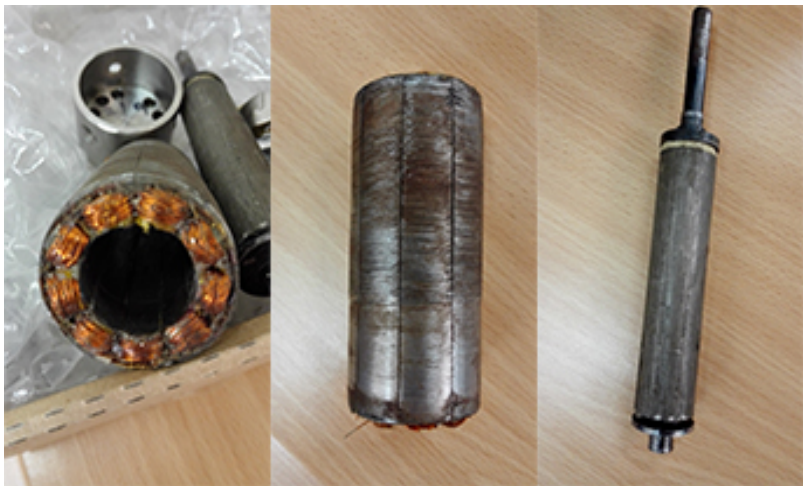

Figure 6. Structure diagram of rotor and stator.

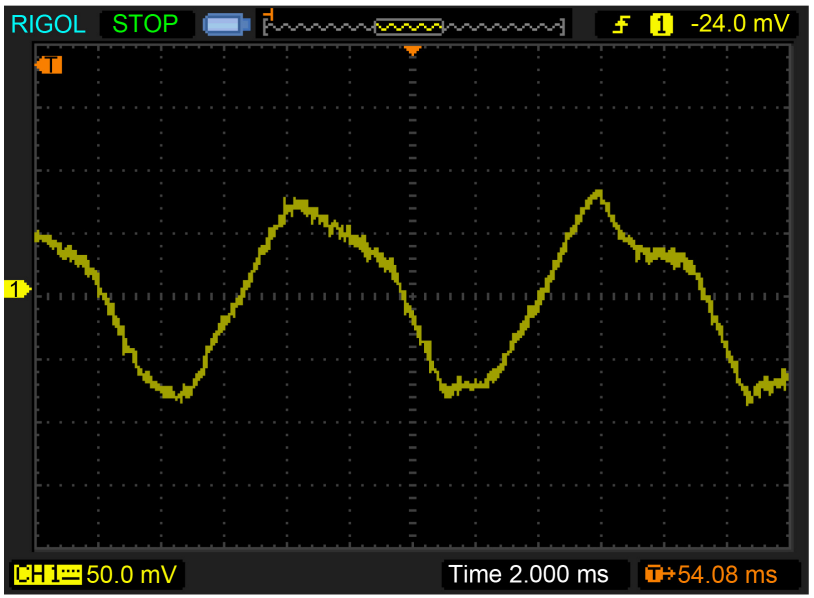

Figure 7. $\mathrm{n}=1570 \mathrm{r} / \mathrm{min}$, Phase current waveform. 


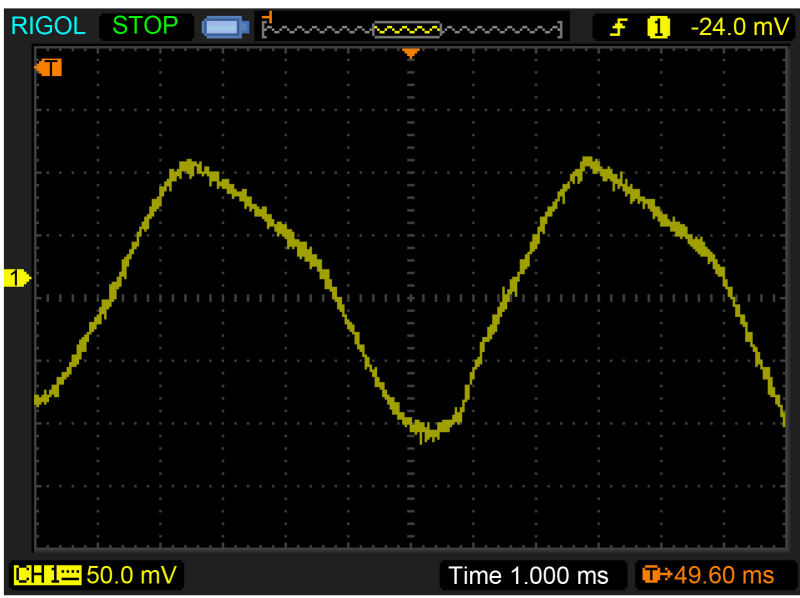

Figure 8. $\mathrm{n}=2370 \mathrm{r} / \mathrm{min}$, Phase current waveform.

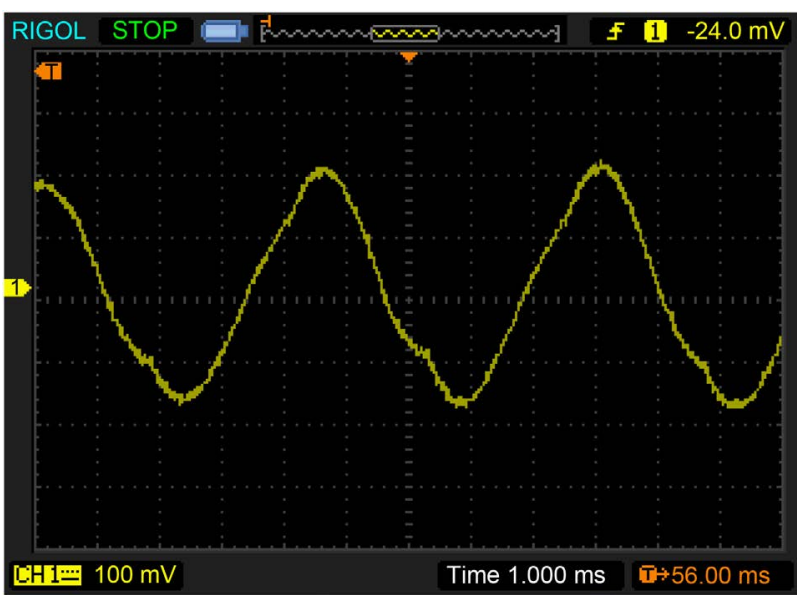

Figure 9. $\mathrm{n}=3350 \mathrm{r} / \mathrm{min}$, Phase current waveform.

Table 2. Motor technical indicators.

\begin{tabular}{cccc}
\hline Rated speed & $3000 \mathrm{r} / \mathrm{min}$ & Stator resistance & $0.0187 \Omega$ \\
Rated power & $4430 \mathrm{w}$ & Straight axis self-inductance & $0.02547 \mathrm{H}$ \\
Rated Voltage & $230 \mathrm{~V}$ & Cross-axis self-inductance & $0.02816 \mathrm{H}$ \\
$\begin{array}{c}\text { Rated torque } \\
\text { Magnetic pole } \\
\text { logarithm }\end{array}$ & $3 \mathrm{~N} \cdot \mathrm{m}$ & Permanent magnet flux linkage & $0.1717 \mathrm{~Wb}$ \\
& 4 & Moment of inertia & $2.26 \times 10^{-5} \mathrm{~kg} \cdot \mathrm{m}^{2}$ \\
\hline
\end{tabular}

conditioner compressor designed in this paper has been tested several times to analyze the control performance of the motor. The results show that the control system can significantly improve the normal operation of the drive motor in the environment of excessive noise and severe system oscillation, and the working ability to meet the actual working conditions of electric vehicle air conditioning compressors.

\section{Conflicts of Interest}

The authors declare no conflicts of interest regarding the publication of this paper. 


\section{References}

[1] Yamada, E. and Zhao, Z.M. (2000) Applications of Electrical Machine for Vehicle Driving System. Proceedings IPEMC 2000: Third International Power Electronics and Motion Control Conference, 3, 1359-1364. https://doi.org/10.1109/IPEMC.2000.883051

[2] Zheng, J.G., Wu, H.X., Zheng, P., Pi, L.P. and Huang, Y.P. (2017) Modeling and Simulation of Speed Loop Control Technology for Permanent Magnet Synchronous Motor Servo System. 2017 IEEE Transportation Electrification Conference and EXpo, Asia-Pacific (ITEC Asia-Pacific), Harbin, 2-5 August 2017, 1-5. https://doi.org/10.1109/ITEC-AP.2017.8080973

[3] Liu, H., Gao, Z., Wu, W., Chow, L. and Wu, T. (2015) Design of a High-Efficiency Permanent Magnet Synchronous Motor and Inverter System. IECON 2015-41st Annual Conference of the IEEE Industrial Electronics Society, Yokohama, 9-12 November 2015, 004996-005001.

[4] Suthamno, K. and Sujitjorn, S. (2012) Modelling of Permanent Magnet Synchronous Motor Incorporating Core-Loss. Open Access Library Journal, 4, 2846-2853.

[5] Zhai, L. and Li, H. (2008) Modeling and Simulating of SVPWM Control System of Induction Motor in Electric Vehicle. 2008 IEEE International Conference on $\mathrm{Au}$ tomation and Logistics, Qingdao, 1-3 September 2008, 2026-2030. https://doi.org/10.1109/ICAL.2008.4636495

[6] Ping, L. and Lan, C. (2012) Study on Controlling and Simulation of Drive System for Permanent Magnet Synchronous Motor in Electrical Vehicle. 2012 Power Engineering and Automation Conference, Wuhan, 18-20 September 2012, 1-4. https://doi.org/10.1109/PEAM.2012.6612509

[7] Yu, L., Wang, C., Shi, H., Xin, R. and Wang, L. (2017) Simulation of PMSM Field-Oriented Control Based on SVPWM. 2017 29th Chinese Control and Decision Conference (CCDC), Chongqing, 28-30 May 2017, 7407-7411.

https://doi.org/10.1109/CCDC.2017.7978524 